\section{Nanofiltration of Natural Organic Matter: Removal, Fouling and the Influence of Multivalent Ions}

A.I. Schäfer' ${ }^{1}$ A.G Fane ${ }^{1}$, T.D. Waite ${ }^{2}$

UNESCO Centre for Membrane Science and Technology, School of Chemical Engineering and Industrial Chemistry, University of New South Wales, Sydney NSW 2052, Australia

A.Schaefer@unsw.edu.au; ph ++61293854370 fax ++6129385 5966

A.Fane@unsw.edu.au; ph ++61293854315 fax ++61293855054

Department of Water Engineering, School of Civil and Environmental Engineering, University of New South Wales, Sydney NSW 2052, Australia

D.Waite@unsw.edu.au; ph ++61293855060fax ++61293856139

\section{ABSTRACT}

The presence of calcium and humic substances or natural organic matter $(\mathrm{NOM})$ in surface waters can cause severe fouling of nanofiltration (NF) membranes. Conditions of fouling were studied using a stainless steel stirred cell of volume $185 \mathrm{~mL}$ and a membrane area of $21.2^{*} 10^{-4} \mathrm{~m}^{2}$ at a transmembrane pressure of 5 bar. Deposition of organic matter was determined by mass balance in feed and concentrate samples. Electron microscopy and X-ray photoelectron spectroscopy (XPS) were used to study the morphology and composition of the fouling layer. During permeate recycle experiments, which were used for fouling studies, it was found that calcium concentration (as a representative which were ued for foulng stules, multivalent ions) and the type of organic play a major role in fouling. The calcium forms complexes with some of the organics and deposits on the membrane surface. Depending on the solution conditions the organic or calcite (on which organics adsorb) precipitate. Factors, which influence the concentration of organics and ions at the membrane surface such as stirring, flux and transmembran pressure, influenced the deposition of organic matter significantly. Irreversible fouling occurred with all membranes at high calcium concentrations, although the cellulose acetate membrane showed an overall better performance, possibly due to its low salt rejection and smooth surface. IHSS humic acid is the organic which deposits most easily and comparison of UV absorbance and DOC data showed that the fraction which absorbs UV strongest, and is more hydrophobic, deposits preferentially on the membranes. These substances also have the lowest solubility stressing the importance of concentration polarisation effects.

\section{KEYWORDS}

Nanofiltration, Fouling, Natural Organic Matter, Humic Substances, Calcium, Mass Transfer.

\section{INTRODUCTION}

In the nanofiltration $(\mathrm{NF})$ of surface waters, organic solutes and multivalent ions are removed via a combination of charge interaction and size exclusion. The conformation of the organic molecules (coiled at low pH, linear chains at high pH) is believed to be important for flux decline $[1,2]$. For natural organic matter both charge and size mechanisms may be important, especially for the natural organic matter both charge and size mechanisms may be important, especially for the
compounds, which are smaller than the NF 'pores'. NF membranes may be porous or non-porous compounds, which are smaller than the NF 'pores'. NF membranes may be porous or non-porous
depending on the material [3]. While NF of surface waters generally achieves a removal of $>90 \%$ of organics high flux decline is common. Hong and Elimelech [4] have previously shown that fouling by $\mathrm{NOM}$ is increased in the presence of calcium ions and that permeation drag and electrostatic double layer repulsion control fouling. Elimelech et al. [5] have noted the importance of membrane roughnes on colloid fouling of membranes however the mechanism of fouling is poorly understood. In this study, experiments were carried out under various solution chemistries, organic and membrane types in order to identify critical fouling conditions. Jucker and Clark [6] have demonstrated a preferential adsorption of hydrophobic compounds on hydrophobic UF membranes. However, Childress and Elimelech [7] showed that humic substances adsorb on hydrophilic membranes very rapidly and that the membrane surface potential becomes more negative due to the humic substances. Calcium facilitates the adsorption of negatively charged organics onto negative surfaces.

The adsorption of organic compounds is an important process; however, adsorption would only be The adorts only be responsble for a rate role concentration polarisation (influenced by hydrodynamic conditions) and solution chemistry on the morphology of the fouling layers. The interactions of calcium and NOM are studied over a wide range of $\mathrm{pH}$ and concentration, contributing to an understanding of the interactions and the impact on NF.

\section{BACKGROUND}

\subsection{Nanofiltration of Natural Organic Matter (NOM)}

Nanofiltration (NF) is a pressure driven membrane process, located between ultrafiltration (UF) and reverse osmosis $(\mathrm{RO})$ and, generally operated at a transmembrane pressure of 3 to 10 bar. The main characteristic of $\mathrm{NF}$ is the selectivity between mono- and multivalent ions, compared to zero ion rejection of most UF membranes and complete ion rejection of RO membranes. However, there is no clear boundary between these membrane classifications, rather UF, NF and RO represents a continuum in 'pore size'.

Parameters used to quantify the efficiency of NF, are flux (J) and solute rejection (R) where the flux is defined as

$$
J \equiv \frac{1}{A} \frac{d V}{d t}
$$

and rejection as

$$
R=100 \cdot\left(1-\frac{c_{P}}{c_{B}}\right)
$$

The amount of deposit of solute on the membranes may be described (using mass balance principles and assuming $100 \%$ rejection) by

$$
M_{D}=V_{F} \cdot c_{F}-V_{C} \cdot c_{C}
$$

This can also be described as loss of solute (in percent of mass in the feed solution)

$$
L_{D}=100 \cdot \frac{M_{D}}{V_{F} \cdot c_{F}}
$$

with deposition and loss calculable for calcium, and organic carbon as DOC or UV.

\subsection{Concentration Polarisation and Osmotic Pressure}

Concentration polarisation is the accumulation of solute due to solvent convection through the membrane. Concentration polarisation leads to a reduced permeate flux either in the form of an osmotic pressure on the feed side (thus reducing the effective transmembrane pressure) or due to the build-up of a region of higher viscosity in the boundary layer (and thus creating an additional resistance to filtration). If concentration polarisation effects are strong, the solute in the boundary layer can reach its solubility limit and cause irreversible fouling. Depending on the concentration of different solutes (in this case calcium and organics), aggregation, coagulation or precipitation may occur possibly after an initial adsorption and determine the structure of the deposit and flux. The concentration of solute in the boundary layer is determined by the equilibrium between convective transport of solute to the membrane and the backdiffusion of the solute into the bulk solution due to the concentration gradient. 
surface. This mass transfer coefficient is in theory independent of the membrane. Equation (5) describes the relationship between flux and concentration of solute at the membrane surface.

$$
J=k_{S} \cdot \ln \frac{\left(c_{W}-c_{P}\right)}{\left(c_{B}-c_{P}\right)}
$$

Equation (6) describes flux as a function of the osmotic pressure which is caused by concentration polarisation.

$$
J=\frac{\Delta P-\Delta \Pi}{\mu \quad R_{M}}
$$

Concentration polarisation may be of particular importance in NF due to a relatively high flux (compared to RO) and a high rejection (compared to UF). Due to low concentrations of solute in surface water treatment applications, concentration polarisation is often neglected. In this study the extent of concentration polarisation is estimated for conditions typical of surface waters.

\subsection{Solubility of Calcium and Natural Organic Matter (NOM)}

The solubility product of humic substances is largely unknown and very difficult to determine due to the complex mixture of compounds present in NOM. Some components of NOM may form insoluble complexes with multivalent ions such as calcium and precipitate on the membrane surface. NOM is expected to contain about $40 \% \mathrm{FA}, 10 \% \mathrm{HA}$ and $50 \%$ undefined compounds of which about $40 \%$ are hydrophilic acids. Fulvic acid (FA) is soluble under acidic and basic conditions while humic acid (HA) is insoluble at low $\mathrm{pH}[8]$. Multivalent ions and $\mathrm{pH}$ reduction decrease the solubility of compounds such as HA as a result, principally, of charge neutralisation effects. Tipping et al. [9] showed that humic solubility increases with its charge. FA has a higher charge than HA. Complexation of NOM with calcium increases with $\mathrm{pH}$ due to a higher dissociation of carboxylic groups [4]. At high $\mathrm{pH}$ and high calcium concentration, calcite precipitates. The NOM then adsorbs on the calcite surface. Suess $[10$, calcium concentration, calcite precipitates. The NOM then adsorbs on the calcite surface. Suess [ hydrated organo-calcium complexes on calcite surfaces. He described the thick layer of organics on the calcite surface as nitrogen-rich, possibly protein-like substances.

\section{MATERIALS AND METHODS}

\subsection{Membranes}

The membranes used were supplied by Fluid Systems (San Diego, U.S.). Three thin film composite (TFC-S, TFC-SR, TFC-ULP) membranes and one cellulose acetate (CA-UF) membrane were used. Charge and rejection characteristics of these membranes were described elsewhere [12]. The membranes have a negative charge at neutral and high $\mathrm{pH}$ and a neutral or slightly positive charge at low $\mathrm{pH}$. The TFC-SR membrane has the highest charge, retains most organics and is very selective; strongly retaining calcium ions compared to sodium ions. The CA-UF membrane has a relatively high strongly retaining calcium ions compared to sodium ions. The CA-UF membrane has a relatively high
organic rejection (about $70 \%$ ), but no salt rejection, thus being on the UF side of NF. Both, TFC-S and organic rejection (about 70\%), but no salt rejection, thus being on the UF side of NF. Both, TFC-S and
TFC-ULP retain large amounts of sodium, calcium and most of the organics, being on the RO side of TFC-ULP retain large amounts of sodium, calcium and most of the organics, being on the
NF. Rejection results at $\mathrm{pH} 8$ for FA (smallest organic used) are summarised in Table 1.

Electronmicrographs of the clean membranes [12] show that the CA-UF membrane has a very smooth surface, whereas the TFC membranes are relatively rough.

\subsection{System}

A schematic of the system used is shown in Figure 1. A magnetic stirrer (Amicon) was used with the stirrer speed calibrated using a stroboscope. Temperature was controlled at $20 \pm 1^{\circ} \mathrm{C}$ using a waterbath. The pressure was set and maintained using an instrument air cylinder. Permeate was collected on a PC-controlled electronic balance.

\subsection{Filtration Protocol}

Two filtration protocols were used in the NF studies, one to determine rejection, and one to determine fouling. For both experiments, $185 \mathrm{~mL}$ of feed solution was placed in the stirred cell after filtration of MilliQ water for $1 \mathrm{~h}$ at $10 \mathrm{bar}$ (for membrane compaction) and $30 \mathrm{~min}$ at $5 \mathrm{bar}$ (for pure water flux determination). $120 \mathrm{~mL}$ of the feed were filtered, which leads at $100 \%$ rejection to a threefold concentration in the cell. For the rejection experiments, three samples of permeate, each of $40 \mathrm{~mL}$ were taken. MilliQ water was then filtered for $30 \mathrm{~min}$ to determine the pure water flux after the experiment. For fouling experiments, the filtrate was recycled into the stirred cell twice without taking samples. This enabled the separation of concentration polarisation effects from fouling effects. One sample was taken from the last permeate and MilliQ water was filtered for at least $30 \mathrm{~min}$ after the experiment to determine if irreversible fouling had occurred. Samples were taken from feed and concentrate to calculate the deposition of solute on the membrane via mass balance. The concentrate was sampled after recycling the permeate to account for the organics in the permeate. A typical fouling experiment is shown in Figure 3. The different stages of the experiment are explained in the legend, the information gained from this experiment can be summarised as I: flux reduction due to osmotic the information gained from this experiment can be summarised as I: flux reduction due to osmotic pressure and concentration polarisation. Both effects increase during the experiment and irreversib
fouling causes further flux decline; II: osmotic pressure, concentration polarisation and irreversible fouling; III: irreversible fouling; IV: irreversible fouling after water wash.

\subsection{Natural Organic Matter (NOM) and Background Solution}

Three types of organics were chosen: Two of these were purified and fractionated organics, purchase from the International Humic Substances Society (IHSS), Suwannee River Reference material, humic (HA) and fulvic (FA) acid. This material allows comparison of results on an international level as this material is easily accessible and well characterised [13]. A third organic type, an Australian NOM was concentrated from Mooney Mooney Dam (Gosford, NSW) using microfiltration and RO to concentrate all surface water constituents. The concentrate was further freeze-dried [14]. The NOM powder obtained includes all inorganic salts and hydrophilic organics, which are part of the surface water. However, organics, which are associated with particulates, are lost and concentration of salt is drawback. It is howeve, impor the the importance of the characteristics of the organics.

The synthetic surface water used, contained $0.5 \mathrm{mM} \mathrm{CaCl}_{2}$ as a representative of naturally occurring The synthetic surface water used, contained $0.5 \mathrm{mM} \mathrm{CaCl}_{2}$ as a representative of naturally occurring
multivalent cations, $1 \mathrm{mM} \mathrm{NaHCO}$ as a natural buffer system, and $20 \mathrm{mM} \mathrm{NaCl}$ as a background multivalent cations, $1 \mathrm{mM} \mathrm{NaHCO} 3$ as a natural buffer system, and $20 \mathrm{mM} \mathrm{NaCl}$ as a backg
electrolyte enabling $\mathrm{pH}$ adjustment without variation of the ionic strength. At high $\mathrm{CaCl}_{2}$ concentrations, $\mathrm{NaCl}$ was added to adjust the conductivity of the solution to $2 \mathrm{mScm}^{-1}$ instead of using background electrolyte. For rejection experiments, $5 \mathrm{mgL}^{-1}$ organic carbon (as DOC) was added, which is characteristic for a typical surface water. For fouling experiments, $12.5 \mathrm{mgL}^{-1}$ organic carbon was used to accelerate fouling. All chemicals were purchased from Ajax Chemicals (Australia). 1M $\mathrm{HCl}$ and $1 \mathrm{M} \mathrm{NaOH}$ were used for $\mathrm{pH}$ adjustment, and $1 \mathrm{M} \mathrm{NaCl}$ for ionic strength adjustment.

\subsection{Analytical Methods}

Samples were characterised by UV/VIS spectrometry using a Varian Cary 1E UV/VIS. Dissolved organic carbon was analysed using a Skalar 12 carbon analyser. A Perkin Elmer Optima 3000 Inductively Coupled Plasma Atomic Emission Spectrometer (ICP-AES) was used to determine cation content of the samples. Samples were diluted with $5 \%$ nitric acid.

Aggregation of the organics was studied under various conditions using a method described by Senesi et al. $[15,16$, and 17]. Solubility was estimated using centrifugation of the aggregate samples under various conditions as described by De Nobily and Contin [18] using a RC5B Sorvall (DuPont) centrifuge at $25000 \mathrm{G}$ for $30 \mathrm{~min}$ at $20^{\circ} \mathrm{C}$

Some of the fouled membranes were characterised using field emission scanning electron microscopy (FESEM) and X-Ray photoelectron spectroscopy (XPS). Samples for FESEM were freeze dried and coated with a thin layer of chromium The samples were then viewed with a Hitachi S-900 microscope at $2 \mathrm{kV}$. No sample preparation was required for XPS for which a KRATOS XSAM800pci instrument with a $\mathrm{MgK} \alpha \mathrm{X}$-ray source (1253.6 eV proton energy, no monochromator) was used. 


\section{RESULTS AND DISCUSSION}

\subsection{Mass Transfer Coefficient and Wall Concentration}

The mass transfer coefficient of the stirred cell was estimated using the method described below. Dextran (T-70) was purchased from Pharmacia Biotech (Uppsala Sweden) and a stock solution of about $60 \mathrm{~g} / \mathrm{L}$ was used. Applying the osmotic pressure model and assuming negligible fouling of the membren can be calculated using equations (5) and (6) and the relationship betwerestic pressure and Dextran concentration, given by Wijmans et al. [19]. The mass transfer coefficient was determined as a function of member within \pm $5 \%$ and thus no impact of the membrane was found. The average mass transfer coefficient at $400 \mathrm{rpm}$ was $(1.81 \pm 0.10)$ E- $6 \mathrm{~ms}^{-1}$. Rejection of Dextran was $>99.5 \%$ for all membranes used. Stirring had large effect on the mass transfer coefficient with the mass transfer coefficients varying from $0.14 \mathrm{E}-6$ $\mathrm{ms}^{-1}$ at $0 \mathrm{rpm}$ (unstirred) to $2.18 \mathrm{E}-6 \mathrm{~ms}^{-1}$ at $560 \mathrm{rpm}$. Knowing the mass transfer coefficient, it is possible to apply equation (5), with $\mathrm{cp}=0$, to predict cw. Figure $2 \mathrm{~A}$ and Figure $2 \mathrm{~B}$ show the estimated surface concentration of calcium and humic acid as a function of flux and mass transfer coefficient, respectively. The larger mass transfer coefficients have been adapted from Da Costa [20]. The value of $9 \mathrm{E}-6 \mathrm{~ms}^{-1}$ is an optimised mass transfer coefficient for an ideal spacer desion. A standard crosslow system would the have a mass transfer coefficient inbeen the optinised and the stirred cell value It can be seen that the concentrations increase rapidly at fluxes approaching $50 \mathrm{Lm}^{-2} \mathrm{~h}^{-1}$, a value commonly achieved with these membranes. The calculations do not consider the concentration during the stirred cell experiments, which could increase the results by a factor of three. It should be noted that the concentrations will not increase indefinitely since a solubility limit will be achieved which depends on the solution chemistry and extent of concentration polarisation. Using Dextran for mass transfer coefficient estimations results in an overestimate of concentration polarisation due to the larger size of Dextran compared to humic substances and calcium. However the diffusion characteristics of humic acid, calcium-humate complexes and even calcium in the highly viscous boundary layer are not known and Dextran is probably a conservative assumption. However, corrections for calcium and HA (molecular weight 1 and $10 \mathrm{kDa}$ ) were done using the hydrodynamic correlations summarised by Suki [21]. The diffusion coefficients were calculated using the StokesEinstein equation at $20^{\circ} \mathrm{C}$ after correlating molecular weight and size (calcium $237 \AA$, HA (1 lDa) 17

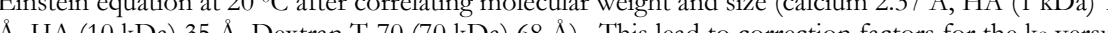
A, HA $(10 \mathrm{kDa}) 35 \mathrm{~A}$, Dextran T-70 $(70 \mathrm{kDa}) 68 \mathrm{~A})$. This lead to correction factors for the ks versu
Dextran of $5.95,2.53$ and 1.56 for calcium, HA $(1 \mathrm{kDa})$ and $\mathrm{HA}(10 \mathrm{kDa})$, respectively.

It is evident from the results that modules with high mass transfer coefficients are important to avoid excessively high values of $\mathrm{cw}$.

\subsection{Solubility of Calcium and Natural Organic Matter}

Chemical equilibrium calculations using the speciation code MinteqA2 [22] of calcium solubility under the conditions used in the experiments indicate that calcite will precipitate at the higher $\mathrm{pH}$ 's investigated. In the absence of organics and at a $\mathrm{pH}$ of 8 this was expected at a concentration of about $3 \mathrm{mM}$. This value will increase in the presence of organics due to interactions with calcium. Organics can inhibit inorganic precipitations, but, given the high degree of uncertainty in calciumorganic Complexation constants, definitive prediction of the effect of NOM on calcite precipitation was not possible. Organic concentrations of $25-75 \mathrm{mgL}^{-1}$ as DOC, $\mathrm{pH} 3.5$ to 10 , calcium chloride concentrations of 0-25 mM, and sodium chloride concentrations of 0-75 mM were tested. Solutions were prepared in $20 \mathrm{~mL}$ sample vials, rapidly shaken after addition of the various stock solutions, $\mathrm{pH}$ adjusted and then the UV scans to measure the aggregation of the organics were carried out after $1 \mathrm{~h}, 5$ $\mathrm{h}$ and $24 \mathrm{~h}$. Precipitation occurred at the $\mathrm{pH}$ extremes at which investigations were undertaken, $\mathrm{i}$. $\mathrm{h}, 5$ h and 24.10 . Th $\mathrm{pH} 3.5$ and $\mathrm{pH}$. The nate of the solids formed at the $\mathrm{pH}$ extremes is very different. At low only HA (not FA and NOM) precipitates. Calcium has no effect on this precipitation, which is observed in the absence of calcium. This effect can be explained by the low solubility of HA,
compared to FA at low pH. NOM is expected to be mainly composed of FA and thus react in a manner similar to FA.
A variation of structure of the aggregates with time was observed for $\mathrm{HA}$ at low $\mathrm{pH}$, indicating that aggregation/precipitation is occurring over several hours after mixing. In the presence of large amounts of $\mathrm{NaCl}(75 \mathrm{mM})$, foam formation was observed. The aggregates formed were very large. Both HA and FA are removed from solution in the presence of $25 \mathrm{mM}$ calcium chloride, however, only at a $\mathrm{pH}$ of 10 , when calcite precipitation is most favourable and the organics are most dissociated and interactions with calcium are strongest. At $\mathrm{pH} 10$ no precipitation occurs in the absence of calcium. This may indicate the precipitation of a calcium-organic complex, co-precipitation of organics with calcite or, simply, adsorption of organics at calcite surface sites.

\subsection{Membrane Filtration}

The rejection of HA, FA and NOM was described elsewhere [12]. This paper describes the critical fouling conditions, which lead to the establishment and verification of fouling mechanisms.

Experiments were carried out at enhanced fouling conditions, thus at $12.5 \mathrm{mgL}^{-1}$ organic carbon and for most experiments increased calcium concentration $(2.5 \mathrm{mM})$. These conditions are extreme for surface waters, but help understand and accelerate fouling and are not unrealistic if one considers the surface waters, but help understand and accelerate fouling and are not unrealistic if one considers the
conditions of modules in a filtration plant operating at 80 to $90 \%$ recovery (i.e. feed concentrated 5 to 10 times).

\subsubsection{Effect of Membrane Type}

The four membranes were tested at two conditions: at normal solution composition as described in section 3.4 and at enhanced fouling conditions. At $0.5 \mathrm{mM} \mathrm{CaCl}_{2}$ no deposition and flux decline occurred. At $2.5 \mathrm{mM} \mathrm{CaCl}_{2}$ measurable deposition and flux decline was observed. Results are shown in Table 2. One would expect increased deposition and flux decline for the membranes with a highe surface roughness [5]. This trend was verified, considering that the flux of the TFC-ULP membrane is lower than that of the other membranes, which would decrease deposition and flux decline. Surface roughness contributes to increased concentration polarisation. The TFC-SR membrane, which is the membrane with the most negative surface charge, showed highest deposition. The TFC-S membrane showed highest flux decline. This membrane however did show compaction effects during the experiments.

\subsubsection{Effect of Organic Concentration and Type}

The results presented in Table 4 show a larger flux decline in the presence of organics compared to pure calcium, although the deposition of calcium is higher in the absence of organics. This shows clearly the effect of inhibition of calcite precipitation by the organics. Comparing the deposition of calcium with the organic type, two possibilities exist: the stronger interaction between calcium and fulvic acid or the higher efficiency of humic acid in the inhibition of calcite precipitation. Jucker and fulvic acid or the higher efficiency of humic acid in the inhibition of calcite precipitation. Jucker and
Clark [6] suggested stronger interaction between HA and calcium, which is also supported with the fact that more hydrophobic compounds are deposited (larger deposit of UV than DOC). Of the organics used, HA has the largest molecular weight and is more hydrophobic that FA and NOM [23]. It is thus suggested that HA is more efficient in the inhibition of calcite precipitation. The reason for this is the higher concentration of large molecular weight compounds in the boundary layer which is evident from mass transfer coefficient estimations The ks increases significantly with a decreasing size of the solute; the concentration in the boundary layer is thus significantly lower for smaller compounds. This was supported by size exclusion chromatography of feed and concentrate samples, where a clear shift towards smaller sizes was observed due to deposition of larger compounds (results not shown).

\subsubsection{Effect of Calcium}

The effect of calcium concentration on flux during recycle experiments is shown in Figure 4 and on the deposit of organics (as DOC and UV) and calcium in Figure 5. TFC-S membranes were used for these experiments. For higher calcium concentrations the flux is lower. The deposition of calcium increases rapidly between 2.5 and $4 \mathrm{mM}$ feed concentration, whereas the deposition of organics is increasing continuously with calcium concentration. At $4 \mathrm{mM}$ the amount of humic acid (or the fraction of HA which interacts readily with calcium) is too small to inhibit calcite precipitation. The water flux ratios after the experiments were $1.13,0.92,0.88,0.68$ and 0.87 for $0,0.5,1.25,2.5$ and 4 $\mathrm{mM} \mathrm{CaCl}_{2}$ respectively. This shows that in the absence of calcium, the HA makes the membrane more 
hydrophilic. A similar effect was observed by Elimelech et al. [4]. The flux has a minimum at $2.5 \mathrm{mM}$ $\mathrm{CaCl}_{2}$ and increases at higher calcium concentrations due to precipitation and the related change in structure of the deposit. Hydrated complexes (as mentioned by Suess [10]) are expected to have a higher flux decline than precipitate. This may explain the lower flux decline at $4 \mathrm{mM} \mathrm{CaCl}_{2}$ although the deposition of calcium and organics are higher (see Figure 5).

\subsubsection{Effect of $\mathrm{pH}$}

The amount of deposit on the membrane as a function of $\mathrm{pH}$ for the TFC-S and TFC-SR membrane is shown in Figure 6. The deposit of organics and calcium increases for both membranes with increasing $\mathrm{pH}$. If charge repulsion were the dominating effect, deposition would be highest at low $\mathrm{pH}$, when membrane and organics have a low charge. This would also favour hydrophobic interactions. Deposition is low, showing that solubility effect and calcium interactions are crucial. At $\mathrm{pH} 8$ the deposit is only loosely bound to the membrane, $50 \%$ of the flux decline car be recovered by deposit is onl wash. At pH 4 and 10 the water membrane. Flux decline is not related to the amount of deposit. It must be assumed that the structure of the deposit is responsible for flux decline rather than the amount; at $\mathrm{pH} 4.5$ the organics are coile and pack very densely on the membrane, at $\mathrm{pH} 8$ complexes form a gel on the membrane which can be removed/dissolved by pure water, and at $\mathrm{pH} 10$ precipitation occurs which is irreversible, but of a more porous structure. The flux prior to water wash is lowest at $\mathrm{pH}$ 8. This hypothesis was verified by electron micrographs. The larger amount of deposit on the TFC-SR membrane at $\mathrm{pH} 10$ shows that deposition increases with membrane charge which may be due to a higher attraction of calcium to the membrane surface.

In all cases more UV than DOC is deposited, showing that the high molecular weight, more hydrophobic and more aromatic compounds are preferentially depositing at all $\mathrm{pH}$ conditions.

\subsubsection{Effect of Pressure and Stirring}

Increased transmembrane pressure causes increased flux and concentration polarisation. Reduced stirring has a very similar impact. The effect of stirring was examined for $12.5 \mathrm{mgL}^{-1} \mathrm{FA}$ and $0.5 \mathrm{mM}$ $\mathrm{CaCl}_{2}$ and the effect of pressure at $12.5 \mathrm{mgL}^{-1} \mathrm{HA}$ and $2.5 \mathrm{mM} \mathrm{CaCl}_{2}$. Results are shown in Table 3 . Both, increased pressure and stirring have a strong effect on deposition and flux. Very interestingly the flux decline with reduced stirring is reversible with pure water, thus indicating a large portion of the flux decline with reduced stirring is reversible with pure water, thus indicating a large portion of the
flux decline is due to concentration polarisation, whereas for increased pressure the flux cannot be flux decline is due to concentration polarisation, whereas for increased pressure the flux cannot
recovered. At reduced stirring the boundary layer would be thicker, whereas at a higher flux the recovered. At reduced stirring the boundary layer would be thicker, whereas at a higher flux the
concentration in the boundary layer is increased. Flux decline is larger than $40 \%$ for CA-UF and TFCconcentration in the boundary layer is increased. Flux decline is larger than $40 \%$ for CA-UF and TFC-
SR at a pressure of 10 bar. This may indicate the presence of a critical flux phenomenon as previously SR at a pressure of 10 bar. This may indicate the presence of a critical flux phenomenon as
explained for microfiltration as the flux below which there is no deposition of colloids on the explained for microfiltration as the flux below which there is no deposition of colloids on the membrane by Howell et al. [24]. For NF this critical flux mate.

\subsection{Electron Micrographs and Deposit Analysis}

The electron micrographs show in many cases a thick gel-like layer on the membrane surface. The morphology of some of the deposits is comparable to a deposit of ferric chloride-organic flocs on microfiltration membranes but at a smaller scale results shown elsewhere [25]. At pH 10 in the

absence of organics, large (up to $5 \mu \mathrm{m}$, square) calcite crystals are visible. In the presence of organics, aggregated spherical colloids of about $100 \mathrm{~nm}$ can be seen. The organics influence the precipitation of the calcite and change the shape of the crystals, which explains the observed difference in flux. Electron micrographs of the calcite crystals, colloids (both pH 10, TFC-S membrane) and calciumorganic 'flocs' (pH 8, CA-UF membrane) are shown in Figure 7 A, B and C, respectively. A deposit of flocs was visible on all four membranes studied. At $\mathrm{pH} 4.5$ the deposit is smoother. With FA less deposit is visible and with NOM the deposit is porous, probably due to the presence of salt in the NOM and the resulting aggregation. This confirms the results of the wall concentration estimation: the solutes pass their solubility limit and form a solid deposit on the membrane.

XPS analysis was carried out of the TFC-S membranes with a calcite deposit, calcium-humate flocs, and the clean membrane, calcium-humate precipitate and pure HA. No calcium was found on the clean membrane. The identification of peaks is difficult due to the complexity of the structure of humic acid and the similarity to the membrane (carboxylic groups). Jucker and Clark [6] suggested the presence of a Ca-humic bond in their measurements at $349.8 \mathrm{eV}$. This result was confirmed with the calcium-humate complex $(349.6 \mathrm{eV})$. On the membranes the chemical shift is different, possibly indicating the presence of a calcite precipitate $(346.7 \mathrm{eV})$ and a calcium-humate complex, but the peaks cannot be resolved due to the small amount of calcium present.

\section{CONCLUSION}

It can be concluded from the above experiments that characterisation of the NOM in a surface water is essential to predict fouling potential. Hydrophobic compounds, often soil derived, deposit preferentially on membranes. At high calcium concentrations fouling is detrimental, with the mechanism depending on solution chemistry. Calcium-humate complexes cause highest flux decline, due to their highly compactable floc-like structure, compared to calcite precipitates. Deposition of calcium and organics increases with $\mathrm{pH}$ due to the precipitation of calcite and adsorption of organics on the calcite surface. HA caused highest flux decline of the three organics used due to its highest concentration in the boundary layer, which was related to its largest molecular weight and thus a lower diffusion away from the membrane. As a result precipitation occurred.

Operation at low flux, low transmembrane pressure and high shear reduces the deposition of insoluble matter at the membrane surface and thus fouling. Fouling could be related to concentration polarisation, which has been calculated for the stirred cell mass transfer coefficient and crossflow systems. Solubility tests showed that in both systems the solubility of calcium is exceeded at the flux typical for NF.

\section{ACKNOWLEDGEMENTS}

The authors would like to thank P. Marks from the Electron Microscope Unit, University of NSW, for specimen preparation and use of instruments. Dr. B. Than-Trong, School of Chemistry, University of NSW, for XPS analysis. Fluid Systems (San Diego, U.S.) are thanked for providing membrane samples and the CRC for Water Quality and Treatment for project funding.

\section{REFERENCES} [1] A. Braghetta, Dissertation, University of North Carolina, Chapel Hill (1995).
[2] K. Ghosh, M. Schnitzer, Soil Science, 129,5 (1980), 266-276. J.M.M. Peeters, Dissertation, University of Enschede, Netherlands (1997)

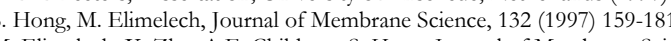
.ence, 127 (1997), 101-109. A E Childress, M, Elimelech, Jour E.M. Thurman, Organic Geochemistry of Natural Waters, Martinus Nijhoff/Dr W. Junk Publishers, Dordrecht (1985).

E.Tipping, C.A. Backes, M.A. Hurley, Water Research, 22,5 (1988) 597-611.

E. Suess, Geochimica et Cosmochimica Acta, 34 (1973) 157-168.

E. Suess, Geochimica et Cosmochimica Acta, 37 (1973) 2435-2447.

A.I. Schäfer, G. Hagmeyer, A. Pihlajamäki, A.G. Fane, T.D. Waite (in preparation).

$[13]$

[14]

A.I. Schäfer, A.G. Fane, T.D. Waite, Proc. International Membrane Science and Technology Conference, Sydney,

[15] N. Senesi, G.F. Lorusso, T.M. Miano, G. Maggipinto, F.R. Rizzi, V. Capozzi, In: N. Senesi, T.M. Miano, (Eds.), 126.

[16] N. Senesi, In: N. Senesi, T.M. Miano, (Eds.), Humic Substances in the Global Environment and Implications on Human Health, Elsevier Science, 1994, pp 3-41.

[17] N. Senesi, F.R. Rizzi, P. Dellino, P. Acquafredda, Soil Sci. Am. J., 60 (1996) 1773-1780.

[18] M. De Nobili, M. Contin, In: N. Senesi, T.M. Miano, (Eds.), Humic Substances in the Global Environment and Implications on Human Health, Elsevier Science, 1994, pp 263-268.

[19] J.G. Wijmans, S. Nakao, J.W.A. Van Den Berg, F.R. Troelstra, C.A. Smolders, Journal of Membrane Science, 22 (1985) $117-135$. 
Schäfer, A.I. Fane, A.G. W Waite, T.D. (1998) Nanofiltration of Natural Organic Matter: Removal, Fouling and the Influence of Multivalent lons, Desalination 118, 109-122 doi:10.1016/S0011-9164(98)00104-0

A.R. Da Costa, Dissertation, University of New South Wales, Chemical Engineering, Sydney (1993)

A.B. Suki, Dissertation, University of New South Wales, Chemical Engineering, Sydney (1984).

Georgia, 1991

作,

25] A.I. Schäfer, A.G. Fane, T.D. Waite, Chemical Addition prior to Membrane Processes for Natural Organic Matter

(NOM) Removal in Water Treatment, $8^{\text {th }}$ International Gothenburg Symposium, Prague, Sept 1998, (in press).

\section{SYMBOLS}

A. Membrane Surface $\left[\mathrm{m}^{2}\right]$

Bulk Concentration $\left[\mathrm{mgL}^{-1}\right]$

Concentrate Concentration $\left[\mathrm{mgL}^{-1}\right.$

Feed Concentration $\left[\mathrm{mgL}^{-1}\right]$

Permeate Concentration [mgL

Flux $\left[\mathrm{Lm}^{-2} \mathrm{~h}^{-1}\right]$

Pure Water Flux prior to Experiment $\left[\mathrm{Lm}^{-2} \mathrm{~h}^{-1}\right]$

Pure Water Flux after Experiment $\left[\mathrm{Lm}^{-2} \mathrm{~h}^{-1}\right]$

Solute Mass Transfer Coefficient [ $\left.\mathrm{ms}^{-1}\right]$

Loss of Solute in Percent of Mass in Feed Solution [\%]

Mass Deposit of Solute on Membrane [mg]

Transmembrane Pressure [bar]
Osmotic Pressure Difference $[\mathrm{b}$

Osmotic Pressure Difference [bar

Rejection [\%]

Timbrane Resistance $\left[\mathrm{ms}^{-1}\right.$

Time [h]

Cermeate Volume $[\mathrm{L}]$

Feed Volume [L]

Viscosity of Solvent (water) [Pa s]

\section{TABLES}

Table 1 Rejection (the three values present rejection after 40, 80 and $120 \mathrm{~mL}$ filtration, respectively) and final flux to pure water flux ratio of membranes $\left(5 \mathrm{mgL}^{-1} \mathrm{DOC} \mathrm{FA}, 0.5 \mathrm{mM} \mathrm{CaCl}_{2}\right.$, $\mathrm{mM} \mathrm{NaHCO}_{3}, 20 \mathrm{mM} \mathrm{NaCl}, \mathrm{pH} 8$ )

\begin{tabular}{lclllll}
\hline Membrane & $\begin{array}{l}\text { Pure Water } \\
\text { Flux } \\
{\left[\mathrm{Lm}^{-2} \mathrm{~h}^{-1}\right]}\end{array}$ & $\begin{array}{l}\text { DOC } \\
\text { Rejection } \\
{[\%]}\end{array}$ & $\begin{array}{l}\mathrm{UV}_{\text {254mm }} \\
\text { Rejection } \\
{[\%]}\end{array}$ & $\begin{array}{l}\text { Ca } \\
\text { Rejection } \\
{[\%]}\end{array}$ & $\begin{array}{l}\text { Na } \\
\text { Rejection } \\
{[\%]}\end{array}$ & $\begin{array}{l}\text { J/Jwo } \\
\text { End } \\
{[-]}\end{array}$ \\
\hline TFC-ULP & $19 \pm 3$ & $72 / 83 / 86$ & $80 / 91 / 93$ & $87 / 92 / 92$ & $83 / 87 / 85$ & 0.37 \\
TFC-S & $49 \pm 6$ & $78 / 83 / 90$ & $93 / 95 / 96$ & $92 / 95 / 96$ & $74 / 85 / 87$ & 0.63 \\
TFC-SR & $46 \pm 6$ & $94 / 94 / 94$ & $94 / 96 / 98$ & $67 / 68 / 68$ & $34 / 40 / 38$ & 0.91 \\
CA-UF & $50 \pm 4$ & $68 / 72 / 72$ & $76 / 88 / 85$ & $17 / 13 / 13$ & $17 / 11 / 10$ & 1.11 \\
\hline
\end{tabular}

Table 2 Effect of membrane type $\left(12.5 \mathrm{mgL}^{-1} \mathrm{DOC} \mathrm{HA}, 2.5 \mathrm{mM} \mathrm{CaCl}_{2}\right)$

\begin{tabular}{lcccccc}
\hline Membrane & $\begin{array}{c}\text { after } \\
\text { recycle 3 } \\
\text { J/ Jwo }\end{array}$ & $\begin{array}{c}\text { after } \\
\text { experiment } \\
\text { Jw/Jwo }\end{array}$ & $\begin{array}{c}\text { after water } \\
\text { rinse } \\
\text { Jw/Jwo }\end{array}$ & $\begin{array}{c}\text { DOC } \\
\text { Loss } \\
{[\%]}\end{array}$ & $\begin{array}{c}\mathbf{U V}_{\text {254nm }} \\
\text { Loss } \\
{[\%]}\end{array}$ & $\begin{array}{c}\text { Calcium } \\
\text { Loss } \\
{[\%]}\end{array}$ \\
\hline TFC-ULP & 0.61 & 0.93 & 0.92 & $9(0.11 \mathrm{mg})$ & 12 & $0.81(1.72 \mathrm{mg})$ \\
\hline TFC-S & 0.39 & 0.68 & 0.79 & $1(0.04 \mathrm{mg})$ & 16 & $0.21(0.41 \mathrm{mg})$ \\
\hline TFC-SR & 0.75 & 0.83 & 0.93 & $15(0.18 \mathrm{mg})$ & 16 & $1.33(2.86 \mathrm{mg})$ \\
\hline CA-UF & 0.83 & 0.90 & 0.97 & $6(0.08 \mathrm{mg})$ & 10 & $0.44(0.92 \mathrm{mg})$ \\
\hline
\end{tabular}


Schäfer, A.I · Fane, A.G · Waite, T.D. (1998) Nanofiltration of Natural Organic Matter: Removal, Fouling and the Influence of Multivalent lons, Desalination 118 , 109-122 doi:10.1016/S0011-9164(98)00104-0

Table 3 Effect of transmembrane pressure $\left(12.5 \mathrm{mgL}^{-1} \mathrm{HA}\right.$ and $\left.2.5 \mathrm{mM} \mathrm{CaCl}_{2}\right)$ and stirring $\left(12.5 \mathrm{mgL}^{-1} \mathrm{FA}\right.$ and $0.5 \mathrm{mM} \mathrm{CaCl}_{2}$ ) on flux and deposition of solute on the membrane

\begin{tabular}{cccccccc}
\hline Membrane & $\begin{array}{c}\text { Stirring } \\
\text { [rpm] }\end{array}$ & $\begin{array}{c}\text { Pressure } \\
{[\mathbf{b a r}]}\end{array}$ & $\begin{array}{c}\text { after } \\
\text { recycle 3 } \\
\text { J/ Jw0 }\end{array}$ & $\begin{array}{c}\text { after } \\
\text { experiment } \\
\mathbf{J w}_{\mathbf{w}} / \mathbf{J}_{\mathbf{w}}\end{array}$ & $\begin{array}{c}\text { DOC } \\
\text { Loss } \\
{[\%]}\end{array}$ & $\begin{array}{c}\mathbf{U V}_{\text {254nm }} \\
\text { Loss } \\
{[\%]}\end{array}$ & $\begin{array}{c}\text { Calcium } \\
\text { Loss } \\
{[\%]}\end{array}$ \\
\hline CA-UF & 400 & 5 & 0.83 & 0.90 & $6(0.08 \mathrm{mg})$ & 10 & $0.44(0.92 \mathrm{mg})$ \\
\hline CA-UF & 400 & 10 & 0.55 & 0.58 & $13(0.17 \mathrm{mg})$ & 16 & - \\
\hline TFC-SR & 400 & 5 & 0.75 & 0.83 & $15(0.18 \mathrm{mg})$ & 16 & $1.33(2.86 \mathrm{mg})$ \\
\hline TFC-SR & 400 & 10 & 0.50 & 0.56 & $20(0.32 \mathrm{mg})$ & 19 & - \\
\hline TFC-SR & 0 & 5 & 0.63 & 0.86 & $23(0.53 \mathrm{mg})$ & 22 & $2.75(0.65 \mathrm{mg})$ \\
\hline TFC-SR & 400 & 5 & 0.87 & 0.98 & $2(0.06 \mathrm{mg})$ & 1 & $1.11(0.24 \mathrm{mg})$ \\
\hline
\end{tabular}

Table 4 Effect of organic type and concentration with TFC-S membrane $\left(12.5 \mathrm{mgL}^{-1} \mathrm{DOC}\right.$ $\mathrm{HA}, 2.5 \mathrm{mM} \mathrm{CaCl}_{2}$

\begin{tabular}{lcccccc}
\hline Organic & $\begin{array}{c}\text { after } \\
\text { recycle 3 } \\
\text { J/ Jwwo }\end{array}$ & $\begin{array}{c}\text { after } \\
\text { experiment } \\
\mathbf{J w}_{\mathbf{w}} / \mathbf{J}_{\mathbf{w}}\end{array}$ & $\begin{array}{c}\text { after water } \\
\text { rinse } \\
\mathbf{J}_{\mathbf{w}} / \mathbf{J}_{\mathbf{w} 0}\end{array}$ & $\begin{array}{c}\text { DOC } \\
\text { Loss } \\
{[\%]}\end{array}$ & $\begin{array}{c}\mathbf{U}_{\mathbf{2 5 4 n m}} \\
\text { Loss } \\
{[\%]}\end{array}$ & $\begin{array}{c}\text { Calcium } \\
\text { Loss } \\
{[\%]}\end{array}$ \\
\hline NOM & 0.47 & 0.84 & 0.84 & $2(0.06 \mathrm{mg})$ & 14 & $0.44(0.92 \mathrm{mg})$ \\
\hline IHSS HA & 0.39 & 0.68 & 0.79 & $1(0.04 \mathrm{mg})$ & 16 & $0.21(0.41 \mathrm{mg})$ \\
\hline IHSS FA & 0.42 & 0.88 & 0.90 & $8(0.14 \mathrm{mg})$ & 11 & $1.33(2.86 \mathrm{mg})$ \\
\hline No organic & 0.61 & 0.98 & 0.93 & - & - & $1.85(3.70 \mathrm{mg})$ \\
\hline
\end{tabular}

Table 5 XPS results for various samples; composition in $\%$ mass concentration

\begin{tabular}{lcccccc}
\hline \multicolumn{1}{c}{ Sample } & $\begin{array}{c}\mathbf{C} \\
{[\%]}\end{array}$ & $\begin{array}{c}\mathbf{O} \\
{[\%]}\end{array}$ & $\begin{array}{c}\mathbf{N} \\
{[\%]}\end{array}$ & $\begin{array}{c}\mathbf{C a} \\
{[\%]}\end{array}$ & $\begin{array}{c}\mathbf{C l} \\
{[\%]}\end{array}$ & $\begin{array}{c}\text { Ca chemical shift } \\
{[\mathbf{e V}]}\end{array}$ \\
\hline TFC-S (clean) & 57 & 26 & 10 & 0 & 5 & N/A \\
\hline IHSS HA (pure) & 54 & 41 & 1 & 1 & 0 & 352.4 \\
\hline IHSS HA + Ca & 61 & 20 & 0 & 7 & 10 & 349.6 \\
\hline Calcite & - & - & - & - & - & 346.7 \\
\hline TFC-S+HA+Ca & 66 & 27 & 5 & 3 & 0 & 347.7 \\
\hline TFC-S+Ca & 67 & 21 & 10 & 1 & 1 & 348.3 \\
\hline
\end{tabular}

\section{FIGURES}

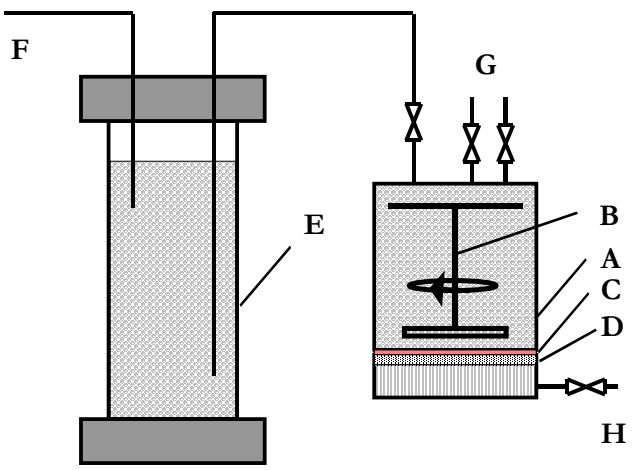

Figure 1 Stainless steel stirred cell set-up A: stirred cell, volume $185 \mathrm{~mL}$; B: magnetic stirrer (Amicon, driven by magnetic stirrer table); C: membrane; D: stainless steel porous support; E: reservoir volume $2000 \mathrm{~mL}$, F: pressurised instrument air inlet, G: feed inlet, pressure release and safety valves;
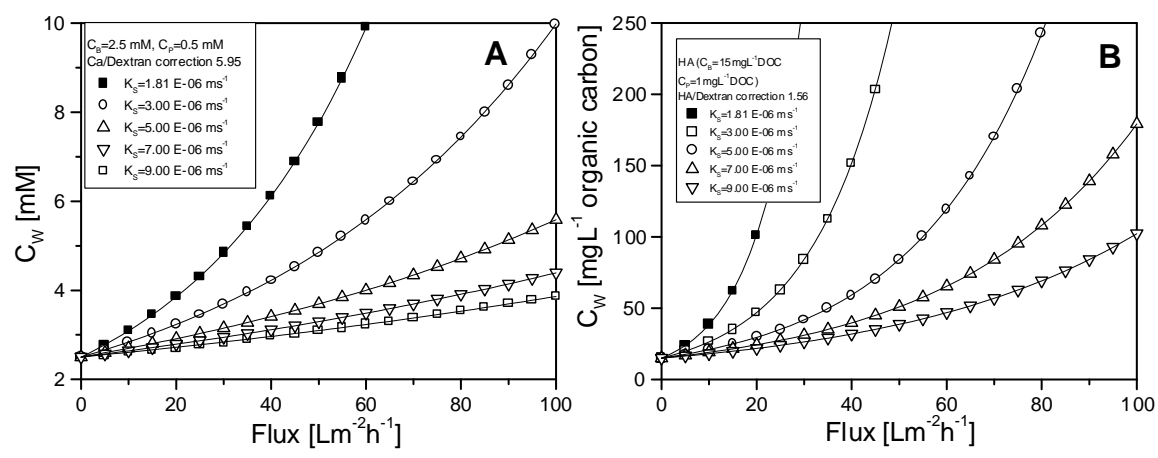

H: permeate outlet (to balance and PC)

Figure 2

Estimated wall concentration of (A) calcium and (B) humic acid (HA) as a function of flux and mass transfer coefficien ( typical of stirred cell; ( $\square$ ) typical of spiral element) 
Schäfer, A.I ; Fane, A.G · Waite, T.D (1998) Nanofiltration of Natural Organic Matter: Removal, Fouling and the Influence of Multivalent lons, Desalination 118 , 109-122
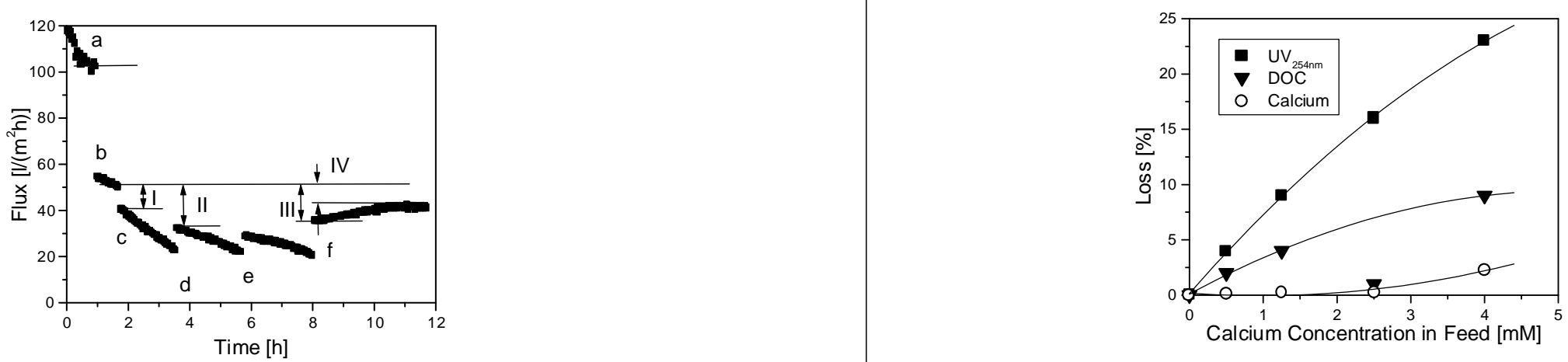

Figure 3 Typical recycle experiment: a: compaction at 10 bar; b: initial pure water flux determination at 5 bar; c: first filtration cycle; d: second filtration cycle; e: third filtration cycle; f: pure water flux determination after filtration

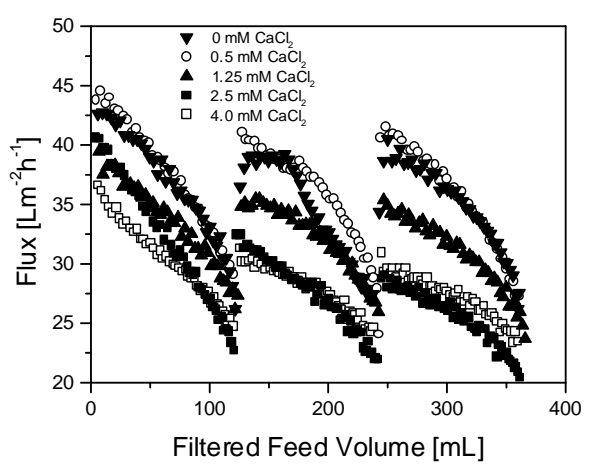

Figure 4 Flux as a function of calcium concentration during recycle experiments (ionic strength adjusted to a constant conductivity of $2 \mathrm{mScm}^{-1}$ using $\mathrm{NaCl}, \mathrm{pH}$ 8)

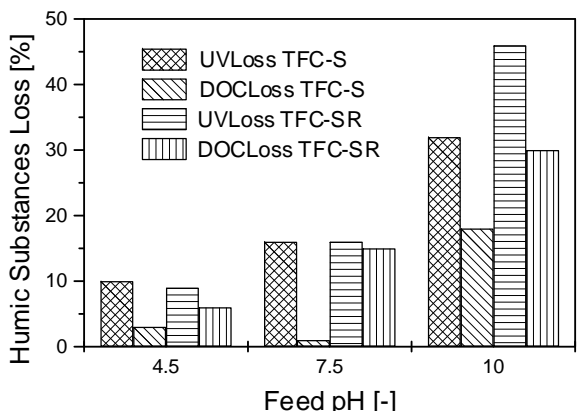

Figure 6 Effect of $\mathrm{pH}$ on deposition of DOC and UV absorbing matter on two membranes (TFC-S and TFC-SR)

Figure 5 Loss of humic acid (as DOC and UV) and calcium as a function of calcium concentration; note that at $4 \mathrm{mM} \mathrm{CaCl}_{2}$ the $8.3 \mathrm{mg}$ of $\mathrm{Ca}$ and $0.62 \mathrm{mg}$ DOC are lost (deposited) 
Schäfer, A.I. ; Fane, A.G. ; Waite, T.D. (1998) Nanofiltration of Natural Organic Matter: Removal, Fouling and the Influence of Multivalent lons, Desalination 118 , 109-122 doi:10.1016/S0011-9164(98)00104-0

14

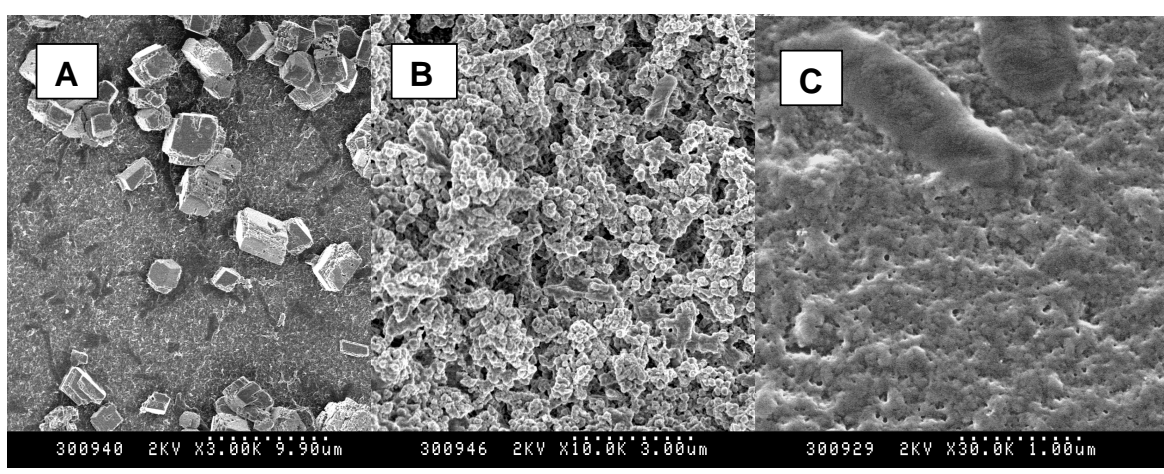

Figure $7 \quad$ Electron micrographs (A) Calcite crystals $\left(\mathrm{pH} 10,2.5 \mathrm{mM} \mathrm{CaCl}_{2}\right)$ : (B) calcite and

organic aggregates (12.5 mgL-1 DOC HA, $\mathrm{pH} 10,2.5 \mathrm{mM} \mathrm{CaCl}_{2}$ ) and (C) $12.5 \mathrm{mgL}^{-1}$ DOC HA, $\mathrm{pH}$, $2.5 \mathrm{mM} \mathrm{CaCl}_{2}$ ) 